\title{
EL POBLAMIENTO RURAL EN TORNO A LUGO EN LA TRANSICIÓN DE LA ANTIGUEDAD AL FEUDALISMO (ss. V-X)
}

Por

\author{
MÓNICA R. LOVELLE - JORGE L. QUIROGA
}

\section{INTRODUCCIÓN: EL MARCO GEOGRÁFICO Y LA RED VIARIA}

La microregión entorno a Lugo ocupa una posición central en la Galicia interior (la denominada «Terra Chá» o meseta interior), delimitada al Este por la Cordillera Cantábrica y al Oeste por la cadena de montañas conocida como la Dorsal gallega. Este territorio se caracteriza por la presencia de dos conjuntos geográficos bien diferenciados: por una parte, el río Miño, que atraviesa este espacio de Norte a Sur y, por lo tanto, toda la zona del valle, cuya altitud media se sitúa por debajo de los $500 \mathrm{~m}$ y que se extiende en sentido Noroeste-Sureste; por otra parte, las zonas montañosas, por encima de los $500 \mathrm{~m}$. de altitud, y que se sitúan a los lados del valle (al Este: la Sierra de Monciro, el Monte Cabana, el «Outeiro Maior», y el «Monte das Madorras»; al Oeste: el «Monte de Porriño», el «Cordal da Pena do Rei», la «Peña de Acevedo», «la Peña de Fornos» y el «Monte do Picato»).

Por lo que respecta a la red viaria, la ciudad de Lugo constituye una verdadera encrucijada de vías romanas: la vía XIX del Itinerario de Antonino (hacia el Sureste y el Oeste), la vía XX (hacia el Noroeste), la vía que se dirigía desde Lugo hacia el Noreste y, finalmente, otras dos vías en dirección hacia el Sur y el Suroeste.

"CUADERNOS DE ESTUDIOS GALLEGOS", Tomo XLVII, Fascículo 113, Santiago 2000. 


\section{EL POBLAMIENTO RURAL EN TORNO A LUGO EN ÉPOCA ROMANA}

Haremos aquí simplemente una breve presentación, desde la perspectiva del análisis espacial de los vestigios arqueológicos y de los lugares de época romana en esta microregión, como punto de partida imprescindible, en nuestra opinión, para el estudio del poblamiento y del territorio en el período denominado de transición al mundo medieval, es decir, entre los siglos V y X.

El mapa de dispersión de hallazgos de época pre-romana y romana, nos muestra la gran densidad de castros $^{1}$, sobre todo en las zonas montañosas que se situan a los lados del valle ${ }^{2}$, que estaban habitados en gran parte por el pueblo pre-romano de los Copori ${ }^{3}$. Entre estos castros debemos de hacer referencia a parte al de Viladonga (Castro de Rei- Lugo), puesto que se trata de un castro muy romanizado y que tendrá una ocupación en época sueva. Tras la fundación de Lucus Augusti, esta ciudad ha servido de polo organizador de los castros que se sitúan en su entorno ${ }^{5}$. Además de la propia ciudad de Lugo, existen otros núcleos en torno a ella que constituyen a su vez verdaderos polos de romanización en esta micro-

\footnotetext{
${ }^{1}$ Se trata de castros con o sin ocupación romana. Cfr. E. GONZÁLEZ FERNÁNDEZ - S. FERRER SIERRA, Catalogación de yacimientos del concello de Lugo, Lugo, 1994; F. ARIAS VILAS - M.C. DURÁN FUENTES, Museo do castro de Viladonga (Castro de Rei-Lugo), Xunta de Galicia, 1996; A. RODRÍGUEZ COLMENERO ed., Lucus Augusti, 1: El amanecer de una ciudad (Catalogación arqueológica y artística de Galicia del Museo de Pontevedra. Fundación Barrié de la Maza), A Coruña, 1996.

${ }^{2}$ Debemos de subrayar la ausencia de castros en el Noroeste y en el Sureste del valle.

${ }^{3}$ A. RODRÍGUEZ COLMENERO ed, Lucus Augusti..., op.cit.

${ }^{4}$ F. ARIAS VILAS- M.C. DURÁN FUENTES, Museo do castro de Viladonga..., op. cit.

${ }^{5}$ Según A.Tranoy, Lugo constituyó un centro de atracción para los habitantes de los castros de la región: A. TRANOY, La Galice romaine. Recherches sur le Nor-ouest de la Péninsule Ibérique dans l'Antiquité, Paris, 1981; Ibd., "Agglomérations indigènes et villes agustéennes dans le Nord-Ouest ibérique «Villes et campagnes dans l'Empire romain, Aix-en-Provence, 1982, p. 131 ss.; Ibd. «Remarques sur la permanence et les mutations dans la Galice antique: le rôle des villes», Portugalia. Nova Serie, IV-V, p.199207; Ibd. «Centralisme, décentralisation ou provincialisation? Aquitaine et Galice d'Auguste à Constantin», Revue Historique, CCLXXII, p. 273-293.
}

"CUADERNOS DE ESTUdIOS GALLEGOS", Tomo XLVII, Fascículo 113, Santiago 2000. 


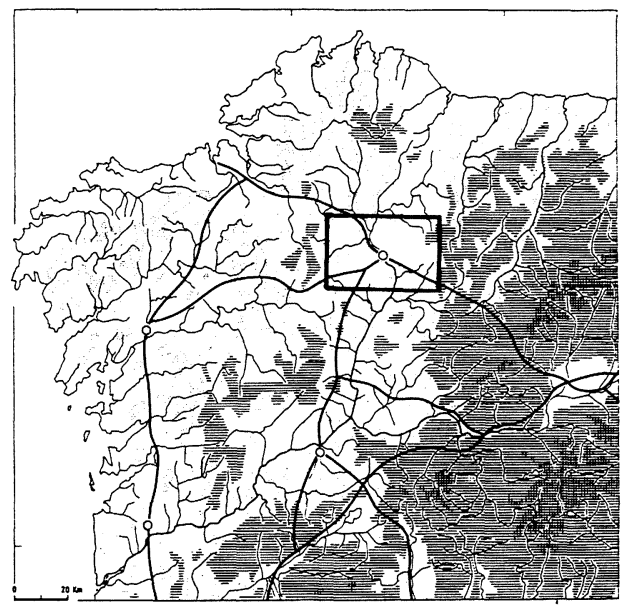

Situación del territorio en torno a Lugo en relación al espacio general.

región: el eje Viladonga-Doncide ${ }^{6}$-Andión ${ }^{7}$-Santa Eulalia de Bóveda ${ }^{8}$ Guntín 9 . Todos estos núcleos ${ }^{10}$, están situados aproximadamente sobre la

${ }^{6}$ Lugar perteneciente a Silva, en Pol, municipio de Lugo y donde se han hallado los vestigios de un hipocausto romano y un mosaico, datados de la segunda mitad del s. III. Tabula Imperii Romani (Hoja K-29), Instituto Geográfico Nacional, Madrid, 1991, p.51.

${ }^{7}$ Lugar también perteneciente a Silva, Pol, municipo de Lugo. Tabula Imperii Romani..., op. cit, p. 22. Aquí, según F. Arias Vilas, habría un castro romanizado. Este mismo autor señala la presencia de una probable villa romana enVila de Arcas (Ansemar, Castro de Rei, Lugo). F. ARIAS VILAS - M.C. DURÁN FUENTES, Museo do castro de Viladonga..., op. cit, p. 46-49.

${ }^{8}$ Donde se habla de la probable presencia de un ninfeo romano. Tabula Imperri Romani..., op. cit., p. 95.

${ }^{9}$ Lugar conocido con el nombre de Aquae Quintiae, ya que se trata de una mansio correspondiente a una vía secundaria. Tabula Imperri Romani..., op. cit., p. 23.

${ }^{10}$ Además de otros vestigios, bien sean de culto (es decir, aras o inscripciones votivas romanas), como en Sinoga (Outeiro de Rei, Lugo), en «A Senra» (Lousada, Guntín, Lugo), en la «Casa do Corgo» (Monte de Meda, Guntín, Lugo): Tabula Imperii Romani..., op. cit., p. 98, 97 y 39 respectivamente, y también en Bouzoá (Arcos, Pol, Lugo): F. PÉREZ LOSADA, Aproximación al poblamiento rural romano del conventus lucensis: las villae, Memoria de Licenciatura inédita, Universidad de Santiago de Compostela, 1986; F. ARIAS VILAS - M.C. DURÁN FUENTES, Museo do castro de Viladonga..., op. cit., p. 50; o bien se trtate de vestigios de tipo funerario: como en Pontegaos (Piugos, Lugo), donde han sido halladas dos inscripciones funerarias romanas (Tabula Imperii Romani..., op. cit., p. 87), F. Arias Vilas menciona además la existencia de una necrópolis romana cerca de Duarría (Castro de Rei-Lugo): F. ARIAS VILAS - M.C. DURÁN FUENTES, Museo do castro de Viladonga..., op. cit., p. 47.

"CUADERNOS DE ESTUDIOS GALLEGOS", Tomo XLVII, Fascículo 113, Santiago 2000. 
línea de $500 \mathrm{~m}$. y en relación con el recorrido de una vía romana.Además, debemos de tener en cuenta la presencia de minas romanas de oro muy cerca del eje Viladonga-Doncide-Andión ${ }^{11}$, lo que explicaría la relativa concentración de núcleos de poblamiento de época romana en esta zona $^{12}$.

\section{EL POBLAMIENTO RURAL EN TORNO A LUGO DURANTE LA ANTIGÜEDAD TARDÍA (SS. V-VII)}

Debemos diferenciar en este período dos momentos diferentes:

\section{a) De principios del s. V a finales del VI}

Para este momento, hay tres núcleos romanos principales: en el centro del territorio, la ciudad de Lugo (intramuros y extramuros), al Oeste Santa Eulalia de Bóveda y al Noreste el castro de Viladonga. El primer cambio o transformación que se observa con claridad es el debido al proceso

\footnotetext{
${ }^{11}$ Sobre las minas de época romana en el noroeste: C. DOMERGUE, Catalogue des mines et des fonderies antiques de la Péninsule Ibérique, (Publications de la Casa de Velázquez, Série Archéologie, VIII), 2 vol., Madrid, 1987; Ibd. Les Mines de la Péninsule Ibérique dans l' Antiquité romaine (Collection de l'Ecole Française de Rome, 127), Roma, 1990; Ibd. «Les explotations aurifères du Nord-ouest de la Péninsule Ibérique sous l' occupation romaine», La minería hispana e ibero-americana. Contribución a su investigación histórica. Estudios, vol.I, León, 1970, p. 151-193; F. SÁNCHEZ - PALENCIA RAMOS, «Las explotaciones auríferas y la ocupación romana en el Noroeste de la península Ibérica «II Seminario de Arqueología del Noroeste, Madrid, 1983, p. 227-246.

${ }^{12}$ «...Asimismo, las explotaciones mineras auríferas de esta época debieron de jugar un importante papel en el contexto arqueológico e histórico de Viladonga, hasta el punto de explicar, por lo menos parcialmente, la organización del territorio y la ocupación de muchos yacimientos. Los restos de minería romana del oro se señalan, por ejemplo, en Corral-Toxeiros Vellos (Castro de Rei, sobre el río Azúmara, llamado «o río do Ouro» en su curso alto...), en Moncelos (Abadín), en el Montefurado del Eo y el Rodil (Ribeira de Piquín), quizás en Arcos (Pol) y en otros lugares del contorno...» F. ARIAS VILAS M.C. DURÁN FUENTES, Museo do castro de Viladonga..., op. cit, p. 49. La relación directa entre establecimientos de época romana y explotación minera es observada también en Asturias: M. FERNÁNDEZ MIER, Génesis del Territorio en la Edad Media. Arqueología del Paisaje y evolución histórica en dos concejos de la montaña asturiana: Miranda y Somiéu, Tesis doctoral inédita, Universidad de Oviedo, 2 vol., 1995.
}

"CUADERnOS DE ESTUdiOs GALLEGOS", Tomo XLVII, Fascículo 113, Santiago 2000. 
de cristianización (tanto en el ámbito urbano como rural). En efecto, los primeros edificios de culto cristiano aparecen entre los siglos IV y V en la propia ciudad de Lugo intra ${ }^{13}$ y extramuros ${ }^{14}$, la capital del antiguo conventus lucense, y en Santa Eulalia de Bóveda, donde el ninfeo romano mencionado es ahora reutilizado como edificio de culto paleocristiano con un importantísimo conjunto de pinturas murales y una piscina central reutilizada a su vez como posible baptisterio ${ }^{15}$. En el momento de la orga-

${ }^{13}$ Bajo la plaza de Santa Maria (inmediata a la Catedral), se hallaron en 1960 un sarcófago antropomorfo en granito, una piscina de tipo paleocristiano y de forma rectangular revestida de mosaico y varias inhumaciones de lajas de pizarra. Todo ello se interpreta (en consonancia con los textos) como un edificio de culto paleocristiano (tipo baptisterio) con una necrópolis asociada, datado de los siglos IV-V: H. SCHLUNK, «Los monumentos paleocristianos de la 'Gallaecia' especialmente los de la provincia de Lugo», Coloquio Internacional sobre el Bimilenario de Lugo, 1977, p. 193-235; F.ACUÑ CASTROVIEJO, Mosaicos romanos de la España Citerior. Conventus Lucense (Studia Arqueologica), 1973, p. 36; J.TRAPERO PARDO, «Hallazgos en la obras de la plaza», Boletín de la Comisión de Monumentos de Lugo, VII (1960-64), p. 95-98; M. VÁZQUEZ SEIJAS, «Piscina romana. Plaza de Santa María de Lugo», Boletín de la Comisión de Monumentos de Lugo, VII (1960-64), p. 272-277.

${ }^{14}$ Como el en actual barrio de San Roque (al exterior de las murallas), donde se ha excavado una gran necrópolis que se prolonga, por lo menos, hasta principios del siglo $\mathrm{V}$, con hallazgos de cerámica común del IV-V y un horno datable en los siglos VI-VII. En la capilla de San Roque se encontró un relieve con decoración típicamente visigoda. En el lugar de Saamasas (mencionado como monasterio en el año 926), se halló un conjunto de 9 piezas de época visigoda: H. SCHLUNK, «Los monumentos paleocristianos...», op. cit., p. 193-235; J. GUERRA «Los restos visigóticos de Saamasas y Lugo «Boletín de la Comisión de Monumentos de Lugo, VIII (1965-70), p. 135-145; A. DEL CASTILLO «Los restos visigóticos de Lugo y Saamasa», Boletín de la Real Academia Gallega, 17 (1928), p. 257-269; M. NÚÑEZ RODRÍGUEZ «Aproximación al estudio de las formas ornamentales en Galicia durante la época visigoda», Revista de Guimarâes, LXXXVI, 1976, p. 177-186; F. HERVES RAIGOSO «Creenzas relixiosas e ritos funerarios IV.7. A necrópole de inhumación de San Roque», Lucus Augusti, Urbs romana. As orixes da cidade de Lugo, Lugo, 1995, p. 126-129.

${ }^{15}$ L.MARTI «Los descubrimientos de Santa Eulalia de Bóveda», Boletín de la Real Academia Gallega, 17 (1928), p. 57-62, 140-142, 165-168, 322-327; M. VÁZQUEZ SEIJAS «Las excavaciones de Santa Eulalia de Bóveda», Boletín de la Real Academia Gallega, XIX (1930), p. 29-31; M. CHAMOSO LAMAS «Sobre el orígen del monumento soterrado de Santa Eulalia de Bóveda (Lugo)», Cuaderno de Estudios Gallegos, XXII (1925), p. 230-251; H. SCHLUNK «Spätrömische und germanische Kunst in Galizien», Primera reunión gallega de estudios clásicos, 1981, p. 277-317; A. RODRÍGUEZ COLMENERO - J.M. VÁZQUEZ VARELA, Arte pehistórico y romano (Galicia Arte. Obra completa, IX), A Coruña, 1993; Ibd - M.C. CARREÑO GASCON, Lucus Augusti..., op. cit., p. 120-121, 133.

"CUADERNOS DE ESTUDIOS GALLEGOS", Tomo XLVII, Fascículo 113, Santiago 2000. 
nización de la red parroquial en la segunda mitad del s. VI (que conocemos a partir de la Divisio Theodomiri o "parroquial suevo» ${ }^{16}$ ), la diócesis de Lugo presentaba un pequeño número de «parroquias», entre las cuales se hacia referencia en primer lugar a «la Iglesia de Lugo y su territorio» ${ }^{17}$, en referencia clara a la noción conocida de la ciudad y su territorio ${ }^{18}$ típica de época romana y plenamente vigente y operativa en este período ${ }^{19}$. Por otra parte, es necesario relacionar la ocupación del castro de Viladonga en este momento, con los acontecimientos políticos que narra Hidacio en su crónica. En efecto, los antiguos castros, han sido utilizados por parte de la población galaico-romana como lugar de refugio frente a los Suevos, poco después de la marcha de los Vándalos ${ }^{20}$. Es lo que Hidacio denomina los castella tutiora, lugares fortificados (tipo castra o castella) desde donde los galaico-romanos se enfrentaron a los Suevos en los numerosos conflictos que tuvieron lugar durante la primera mitad del s. $\mathrm{V}^{21}$. Además, el establecimiento de una base territorial sueva alrededor de Lugo durante la «guerra civil» (poco después del 455 ) $^{22}$, nos indica que el terri-

${ }^{16}$ P. DAVID, Etudes historiques sur la Galice et le Portugal du VIe au XIIe siècles, Paris-Lisboa, 1947.

${ }^{17} \mathrm{Ibd}$.

${ }^{18} \mathrm{P}$. PALOL «Problema ciudad-campo en el bajo-imperio en relación a la ciudad de Lugo», Actas del Coloquio Internacional sobre el Bimilenario de Lugo, Lugo, 1977, p. 157-173.

${ }^{19}$ R. REVUELTA CARBAJO, La ordenación del territorio en Hispania durante la Antigüedad tardia. Estudio y selección de textos, Madrid, 1997; J. LÓPEZ QUIROGA M. RODRÍGUEZ LOVELLE, «La relation ville-campagne au Nord-Ouest de la péninsule Ibérique: un regard depuis le haut Moyen Age»,Villes et campagnes en Gaule romaine (Actes du 120 congrès national des sociétés historiques et scientifiques, Aix-enProvence, 1995), Paris, 1998, p. 189-213.

${ }^{20}$ J. LÓPEZ QUIROGA- M. RODRÍGUEZ LOVELLE, «De los Vándalos a los Suevos en Galicia: Una visión crítica sobre su instalación y organización territorial en el noroeste de la península Ibérica en el siglo V», Studia Historica. Historia Antigua. 13-14 (1995-96), p. 421-436.

${ }^{21}$ «...plebem, quae castella tutiora retinebat, acta suorum partim caede, partim captivitate...», A. TRANOY, Hydace. Chronique, 2 vol. (Sources chrétiennes, $\mathrm{n}^{\circ} 219$ ), Paris, 1974, vol. I, § 91, p. 130-131, vol. II, § 91, p. 63.

${ }^{22}$ J.LÓPEZ QUIROGA - M.RODRÍGUEZ LOVELLE «De los Romanos a los Bárbaros: la instalación de los Suevos y sus consecuencias sobre la organización territorial en el Norte de Portugal (411- 469)», Studi Medievali (Centro Italiano di Studi sull' alto medioevo), 1998, en prensa; Ibd. «De los Vándalos a los Suevos en Galicia...», op. cit., p. 421-436.

"CUADERNOS DE ESTUDIOS GALLEGOS", Tomo XLVII, Fascículo 113, Santiago 2000. 


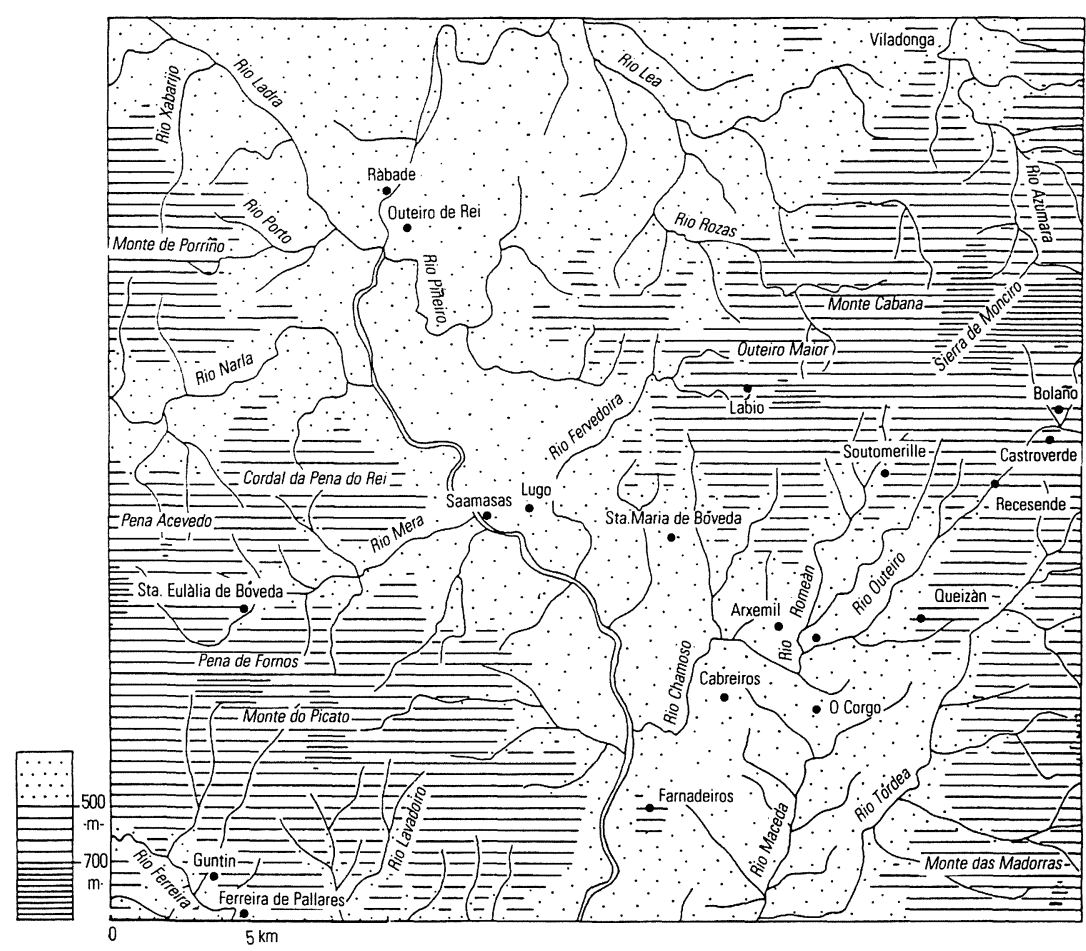

Mapa de presentación del territorio entorno de Lugo.

torio en torno a Lugo, y más concretamente el castro de Viladonga, ha de ser interpretado como un importante lugar fortificado durante este perío$\mathrm{do}^{23}$. No olvidemos queViladonga presenta una gran cantidad de material tardío y una clara fase de ocupación sobre la parte más elevada del castro, que se prolonga, al menos, hasta el s.VI. Para Arias Vilas, se trata de un castro principal, a causa de la probable concentración en Viladonga de

\footnotetext{
${ }^{23}$ Lugar fortificado en el sentido señalado por R.Revuelta Carbajo, con el que coincidimos totalmente en la interpretación a partir de las fuentes de lo que es un castra o un castella en el período tardoantiguo: R. REVUELTA CARBAJO: La ordenación del territorio en Hispania..., op. cit.; J. LÓPEZ QUIROGA-M. RODRÍGUEZ LOVELLE «De los Vándalos a los Suevos en Galicia...», op. cit. p. 421-436; Ibd. «De los Romanos a los Bárbaros...», op. cit.; Ibd. «Castra-Castella de época sueva en el noroeste de la Península Ibérica: ensayo de inventario tipológico», Hispania Antiqua, XXXIII, 1998, en prensa.
} 
población proveniente de otros castros próximos y más pequeños desde el s. III $^{24}$. Viladonga constituye, por lo tanto, uno de los más claros ejemplos de castella tutiora mencionados por Hidacio en su crónica ${ }^{25}$. Por otra parte, la persistencia e incluso la intensificación de la presencia de castros romanizados en el noroeste, parece caracterizar no solamente el período del Bajo-Imperio ${ }^{26}$, sino todo el período que consideramos como Antigüedad tardía (ss. V- VII), sobre todo en la parte interior del antiguo conventus lucense ${ }^{27}$. En este sentido, debemos señalar la existencia de toda una serie de castros alrededor de Santa Eulalia de Bóveda ${ }^{28}$, a proximidad de los cuales se documentan pequeños cementerios de tumbas antropomorfas excavadas en la roca. La continuidad de los castros romanizados en tanto que forma de hábitat ${ }^{29}$ (sobre todo, e insistimos en ello, en las zonas montañosas del interior ${ }^{30}$ ) y la progresiva cristianización de los núcleos

${ }^{24}$ «...Incluso es posible que el Castro de Viladonga «absorbiese» y concentrase a partir del s. III la población de otros castritos cercanos más pequeños (como A Rodela de Valmonte o el Castrelo de Viladonga) o que éstos quedasen como simples enclaves defensivos estratégicos, existiendo así, hipotéticamente, una especie de «estratigrafía»o sucesión horizontal entre yacimientos...», F. ARIAS VILAS - M.C. DURÁN FUENTES, Museo do castro de Viladonga..., op. cit, p.130.

${ }^{25}$ Idea en la que coincide también F. Arias Vilas: cfr. supra, nota 24.

${ }^{26}$ A.TRANOY, La Galice romaine..., op. cit. Debemos de subrayar que la mayor parte de los castros poseen un nivel arqueológico de época tardo-romana en la parte más elevada del asentamiento. Para P. Paolol, podemos hablar de castros romanizados, más que de una población propiamente romana. P. PALOL «Problema ciudad-campo en el bajo-imperio en relación a la ciudad de Lugo...», op. cit., p. 160.

${ }^{27}$ Como sucede en el territorio en torno al monasterio de Samos: J. LÓPEZ QUIROGA - M. RODRÍGUEZ LOVELLE «Le peuplement de moyenne montagne en Galice (Espagne) du Ve au Xe siècle: une introduction à l' étude de l' habitat rural du haut moyen âge à partir d' un espace micro-régional, le territoire de Sarria», Moyenne Montage (Actes du 117 Congrès National des Sociétés Savantes, Clermont- Ferrand, Octobre 1992), Paris, 1995, p. 121-140; M. RODRÍGUEZ LOVELLE, Du Golfe Cantabrique au Miño: Histoire et Archéologie du peuplement entre l'Antiquité tardive et le haut moyen âge, Tesis doctoral inédita, Universidad de Paris-Sorbonne (Paris- IV) - Universidad de Santiago de Compostela, 1998.

${ }^{28}$ N. ARES VÁZQUEZ «Castros entorno a Santa Eulalia de Bóveda», Boletín de la Comisión de Monumentos de Lugo, VIII (1965-70), p. 183- 193.

${ }^{29}$ Fenómeno comparable al que se produce en el occidente de Asturias: M. FERNÁNDEZ MIER, Génesis de territorio en la Edad Media..., op. cit. Ibd. «Transformación del poblamiento en la transición del mundo antiguo al medieval en la montaña asturiana (Península Ibérica)», Archeologia Medievale, XIII (1996), p. 101-129.

${ }^{30}$ Como en torno a Samos: cfr. supra nota $n^{\circ} 27$.

"CUADERNOS DE ESTUdIOS GALLEGOS", Tomo XLVII, Fascículo 113, Santiago 2000. 


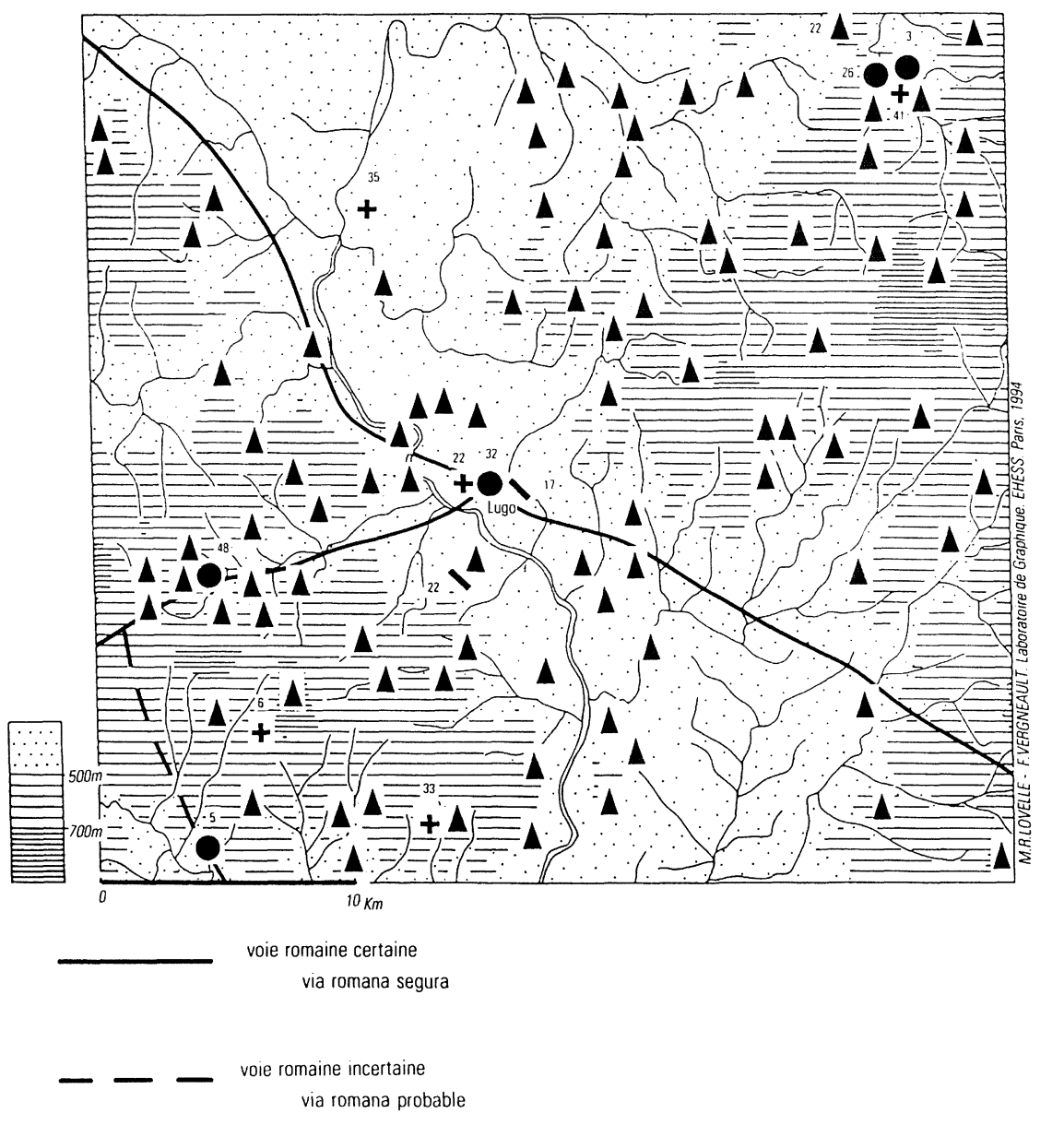

LEEENDE

Leyenda

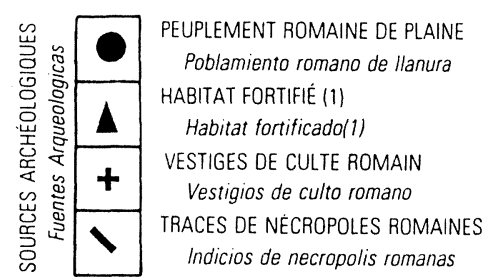

(11. Castros romanisés et non romanisés (1) Castros romanizados y no romanizados

El territorio entorno a Lugo: El poblamiento rural en la época romana. 
romanos más importantes, son los dos fenómenos característicos de la evolución del poblamiento y del territorio en torno a Lugo durante la Antigüedad tardía ${ }^{31}$.

\section{b) De finales del VI a comienzos del s.VIII}

La ciudad de Lugo, durante este período, ha sido objeto de una fase de expansión en las zonas extramuros, con la construcción de nuevos edificios de culto ${ }^{32} \mathrm{y}$, al mismo tiempo, todo ello enmarcado en un proceso bizantinización como consecuencia de la integración de este territorio en el reino visigodo de Toledo $^{33}$. Fenómenos similares se observan igualmente en lo que respecta al mundo rural, en lo que es el territorio en torno a Lugo. Por una parte, se observa la expansión del proceso de cristianización desde la ciudad al campo: así encontramos vestigios de culto enmarcables entre finales del VI y finales del s.VII, en Ferreira de Pallares ${ }^{34}$, en

"Como A. TRANOY defiende para el período del Bajo-Imperio. Este período que analizamos, entre el V y finales del VI, se presenta como una «continuidad» respecto al anterior. Nos referimos, evidentemente, a las líneas generales de evolución del poblamiento, sin negar que haya «rupturas»y, sobre todo, transformaciones. Es por ello, que la imagen que nos ofrece el mapa del poblamiento entre el V y el VII, debe de ser completada con la del poblamiento en época romana.

$32 \mathrm{~J}$. LÓPEZ QUIROGA - M. RODRÍGUEZ LOVELLE «El mundo urbano en la 'Gallaecia' (Conventus Lucense - Conventus Bracarense) entre la antigüedad tardía y la alta edad media (siglos IV- X)», Actas del IV Congreso de Arqueología Medieval Española. Sociedades en transición, Alicante, 1994, p. 47- 57; Ibd. «De la cité antique aux évêchés du haut moyen âge en Galice et Nord du Portugal (IVe- XIe siècles): continuités, ruptures, transformations, La ville au Moyen Age (Actes du 120 Congrès des sociétés historiques et scientifiques, Aix-en-Provence, Octobre 1995), Paris, vol. II, 1998, p. 934; $I b d$. «Reflexiones en torno al concepto de 'urbs' entre la Antgüedad tardía y la alta edad media», Los orígenes de la ciudad en el noroeste hispánico (Actas del Congreso Internacional celebrado en Lugo, Mayo de 1996), Lugo, en prensa.

${ }^{33}$ J. LÓPEZ QUIROGA - M. RODRÍGUEZ LOVELLE, «Reflexiones en torno al concepto de 'urbs'...», op. cit.; L.A. GARCÍA MORENO, Historia de España visigoda, Madrid, 1989.

${ }^{34} \mathrm{Se}$ trata de dos fragmentos de plaqueta de época visigoda. Este lugar está, sin duda, en relación con la mansio de época romana de Aquae Quintiae (Guntín, Lugo). F. VÁZQUEZ SACO «La Iglesia parroquial de Santa María de Ferreira de Pallares», Boletín de la Comisión Provincial de Monumentos de Lugo, IV (1950), p. 37-44; J. GUERRA «Algunos restos visigótico-mozárabes de la provincia de Lugo», Boletín de la Comisión Provincial de Monumentos de Lugo, IX (1971- 72), p. 17- 24; M. NÚÑEZ RODRÍGUEZ «Aproximación al estudio de las formas ornamentales de época visigoda...», op. cit., p. 177- 186

"CUADERNOS DE ESTUDIOS GALLEGOS", Tomo XLVII, Fascículo 113, Santiago 2000. 
San Juan da Pena ${ }^{35}$, en Santa María de Bóveda ${ }^{36}$, en Santa María de Mosteiro $^{37}$, y en Pousada ${ }^{38}$. El proceso de cristianización rural se desarrolla por lo tanto notablemente tras la integración de este espacio en el reino visigodo (y, sin duda, con la influencia de la acción evangelizadora de San Martín de Braga). Por otra parte, existe el problema del hábitat fortificado en este período. ¿Qué ha pasado con el castro de Viladonga a partir de finales del s.VI? En primer lugar, debemos insistir sobre la presencia en Viladonga de una serie de materiales con una fuerte influencia bizantina, lo que constituye una característica para este período en el noroeste ${ }^{39}$. ¿Se trata de la última etapa de la romanización del castro de Viladonga? ¿Qué sucede después? El problema fundamental, en nuestra opinión, es la ausencia de materiales y, por lo tanto, de elementos de datación precisos más allá del siglo $\mathrm{VI}^{40}$, pero, en nuestra opinión, se trata más bien de una dificultad intrínseca a la investigación arqueológica sobre este período y a un desconocimiento total del mismo. Así, en este sentido, algunos «curiosos» hallazgos de Viladonga nos parecen dignos de ser señalados:

${ }^{35}$ Se trata de un capitel con hojas de acanto, típico de época visigoda. R. LÓPEZ PACHO «Vestigios del período pre-románico en la provincia de Lugo», XV Congreso Nacional de Arqueología, Lugo, 1979, p. 1221- 1228; M. NÚÑEZ RODRÍGUEZ, Arquitectura prerrománica en Galicia, La Coruña, 1978, p.66.

${ }^{36}$ En este lugar han sido hallados varios capiteles de época visigoda. J. GUERRA «Algunos restos visigótico- mozárabes de la provincia de Lugo...», op. cit., p. 23.

${ }^{37}$ Proveniente de este lugar se conserva en el Museo Arqueológico Provincial de Lugo un capitel de época visigoda. A. LÓPEZ VALCARCEL «Santa María de Lamas de Moreira y Santa María de Mosteiro», Boletín de la Comisión Provincial de Monumentos de Lugo, VII (1960- 64), p. 266- 270; M. NÚÑEZ RODRÍGUEZ, Arquitectura prerrománica..., op. cit., p. 83.

${ }^{38}$ En Pousada (Baralla- Lugo) se halló una celosía datada de finales del VI o de comienzos del s. VII. R. LÓPEZ PACHO «Vestigios del período prerrománico en la provincia de Lugo»..., op. cit., p. 1221- 1228; M. NÚÑEZ RODRÍGUEZ «Aproximación al estudio de las formas ornamentales durante la época visigoda...». op. cit., p. 177- 186.

${ }^{39} \mathrm{~J}$. LÓPEZ QUIROGA - M. RODRÍGUEZ LOVELLE «Reflexiones en torno al concepto de 'urbs'...», op, cit.; J. LÓPEZ QUIROGA, Du Miño au Douro: Histoire et Archéologie du peuplement entre l'Antiquité tardive et le haut moyen âge, Tesis doctoral inédita, Universidad de Paris-Sorbonne (Paris- IV) - Universidad de Santiago de Compostela, 1997; M. RODRÍGUEZ LOVELLE, Du Golfe Cantabrique au Miño..., op. cit. Influencia bizantina que se produce tras la llegada al trono de Leovigildo: L.A. GARCÍA MORENO, Historia de España visigoda..., op. cit.

${ }^{40}$ Problema común a otros yacimientos no sólo en el noroeste.

"CUADERNOS DE ESTUDIOS GALLEGOS", Tomo XLVII, Fascículo 113, Santiago 2000. 
- un gran edificio alargado, sin material arqueológico asociado, que presenta numerosos huecos de poste excavados en el suelo ${ }^{41}$.

- una gran abundancia de agujeros excavados en el substrato rocoso, localizados en el sector más elevado del castro, tratándose en su mayor parte, de huecos de poste ${ }^{42}$.

Además, Viladonga ha podido jugar un papel de puesto de control o de vigilancia en época visigoda dada su proximidad y posición privilegiada respecto a Lugo (posible capital ducal de la Gallaecia desde la segunda mitad del siglo VII ${ }^{43}$ ), y cerca de una antigua vía romana hacia Asturias ${ }^{44}$. De todo ello, podemos deducir la continuidad del hábitat fortificado de altura tipo castro (y su coexistencia con el hábitat de llanura tipo villae) durante este período ${ }^{45}$.

${ }^{41}$ «En el castro se descubrió también una gran construcción alargada que no es, sin duda, una vivienda más; su tamaño y el hecho de que apenas haya proporcionado materiales ni hallazgo ninguno, inducen a pensar que su función debió de ser social o quizás religiosa, ritual o algo semejante (?), siendo los agujeros aparecidos en su suelo posibles pozos o lugares para ofrendas, más que depósitos tipo silo o similares, sin que ninguna hipótesis se pueda descartar por el momento...», F. ARIAS VILAS - M.C. DURÁN FUENTES, Museo do castro de Viladonga ..., op. cit., p. 61. Debemos destacar el gran número de casas cuadrangulares en Viladonga, por lo tanto, de época tardía.

42 «...Hay esparcidos por casi toda la croa del Castro unos agujeros o concavidades hechas en la roca, de muy diferentes formas y tamaños y de uso diverso. En algunos casos, quizás la mayoría, son agujeros para hincar los postes o pontones que sostenían los techos de las construcciones de piedra (o de los cobertizos o alpendres anejos), pero en otros pueden ser depósitos para el agua o silos para el grano u otros productos (por medio de ollas, cestos, odres, etx.), sin descartar la idea de que a veces los haya también de simple hechura natural de la roca...», F. ARIAS VILAS - M.C. DURÁN FUENTES, Museo do castro de Viladonga..., op. cit., p. 68.

${ }^{43}$ J. LÓPEZ QUIROGA - M. RODRÍGUEZ LOVELLE «De los Suevos a los Visigodos en Galicia (573-711): Nuevas hipótesis sobre el proceso de integración del noroeste de la península Ibérica en el reino visigodo de Toledo», Romano-Barbarica, 1998, en prensa; M. RODRÍGUEZ LOVELLE, Du Golfe Cantabrique au MIño..., op. cit.; R. REVUELTA CARBAJO, La ordenación del territorio en Hispania..., op. cit.

${ }^{44}$ Es necesario destacar la importancia del control de la red viaria de penetración hacia la Asturia transmontana en este período. J. LÓPEZ QUIROGA - M. RODRÍGUEZ LOVELLE «De los Suevos a los Visigodos en Galicia (573-711)...», op. cit.; M. RODRÍGUEZ LOVELLE, Du Golfe Cantabrique au Miño..., op. cit.

${ }^{45}$ J. LÓPEZ QUIROGA, Du Miño au Douro..., op. cit.; M. RODRÍGUEZ LOVELLE, Du Golfe Cantabrique au Miño..., op. cit.; R. REVUELTA CARBAJO, La ordena-

"CUADERnOS DE eSTUdios GALLEGOS", Tomo XLVII, Fascículo 113, Santiago 2000. 


\section{EL POBLAMIENTO RURAL EN TORNO A LUGO EN EL PE- RÍODO DE LA MONARQUÍA ASTURIANA (SS. VIII-X)}

Para este período, y en lo que a fuentes de información se refiere, debemos diferenciar por una parte los vestigios de edificios de culto ${ }^{46}$, vestigios de necrópolis (bien sean tumbas antropomorfas excavadas en la roca $^{47}$, sarcófagos $^{48}$, u otro tipo de inhumaciones ${ }^{49}$ ) y huellas de hábitat

cion del territorio en Hispania..., op. cit.; J. LÓPEZ QUIROGA - M. RODRÍGUEZ LOVELLE «Poblamiento rural en el noroeste de la península Ibérica (ss.V- XI): una introducción al estudio del poblamiento rural entre la antigüedad tardía y la alta edad media a través de un análisis micro-regionali’, Boletín de Arqueología Medieval, 7 (1993), p. 21-53; Ibd. «Le peuplement de moyenne montagne...», op. cit., p. 121-140.

${ }^{46}$ En Soutomerille (Castroverde, Lugo), donde se halló una ventana de tipo mozárabe con arcos de herradura; en San Salvador de Toirán (Láncara, Lugo), se encontró un capitel pre-románico reutilizado posteriormente; en San Juan da Pena (Lugo), la antigua iglesia pre-románica posee un ábside de arco de herradura excavado en la roca, juntamente con una basa de columna y un sillar con decoración pre-románicas; en el lugar de «Agro do Santo», en Conturiz (San Andrés de Castro, Lugo), donde ha sido identificado recientemente un edificio de tipo pre-románico; en Santa Eulalia de Bóveda (Lugo), se observan reformas en el edificio de culto paleocristiano datables de época asturiana, como lo muestran los capiteles y modillones enmarcables en ese período; y, finalmente, en la propia catedral de Lugo, con vestigios contructivos también de época asturiana.

${ }^{47}$ Como en Recesende (Castroverde, Lugo); en Queizán d' Abaixo (Santa María de Queizán, Corgo, Lugo); en Santa María de Cabreiros (Corgo, Lugo); en el «Monte Couso» (San Vicente do Burgo, Lugo); en San Matías (San Vicente de Veral, Lugo); en Pena Liñar (San Julián de Vilachá de Mera, Lugo); en el «Monte Cubelo», en el lugar de Facoi (San Julián de Vilachá de Mera, Lugo); cerca de la capilla de Nuestra Señora del Rosario, en Bravos (San Pedro de Villalvite, Friol, Lugo); y, naturalmente, en la propia ciudad de Lugo, en el $n^{\circ} 13$ de la calle «Carril dos Loureiros y ${ }^{\circ} 185-186$ de la «Ronda da Muralla».

${ }^{48}$ Como en Santa Eulalia de Bolaño (Castroverde, Lugo); en Rebordaos (Castroverde, Lugo); en Outeirín (San Ciprián de Recesende, Castroverde, Lugo); en Santa María do Monte (Castroverde, Lugo); en San Esteban de Paderne (Castroverde, Lugo); en Vidueiros (San Ciprián de Montecubeiro, Castroverde, Lugo); en Zolle (Guntín, Lugo); en San Salvador de Outeiro (Lugo).

${ }^{49}$ Como inscripciones funerarias en Santa Comba de Orizón (Castro de Rei, Lugo); en San Juan de Tirimol (Lugo); en Rábade (Lugo); en Armental (Santiago de Gomelle, Guntin, Lugo); en Soutomerille (Castroverde, Lugo); en Arxemil (Corgo, Lugo); en San Cristóbal de Chamoso (Corgo, Lugo).

"CUADERNOS DE ESTUDIOS GALLEGOS", Tomo XLVII, Fascículo 113, Santiago 2000. 
fortificado ${ }^{50}$, en lo que respecta a las fuentes arqueológicas; por otra parte, tenemos varias menciones de villas $^{51}$, de ecclesia ${ }^{52}$, y de monaste$\operatorname{rios}^{53}$, en lo que respecta a la información documental.

Debemos diferenciar, como hemos hecho para el período anterior, dos momentos:

- un primer momento, despúes de la invasión árabe. Como observamos en el mapa correspondiente a este período, contamos con ocho lugares situados alrededor de Lugo en donde han sido hallados pequeños

\footnotetext{
${ }^{50}$ Como en la cumbre del monte «do Castelo» en Labio (Lugo), donde se halló el derrumbe de una torre medieval; lugar, por otra parte, mencionado en la documentación como castellum en 998-999, y concedida por el rey Bermudo III a la sede episcopal lucense en 1032. Se trata de un lugar de gran valor estratégico. E. GONZÁLEZ FERNÁNDEZ - S. FERRER SIERRA, Catalogación de yacimientos del concello de Lugo..., op. cit. ( $\mathrm{n}^{\circ} 81$ del catálogo).

${ }^{51}$ Como en Rábade, mencionada en 997, 999 y 1028; en la Robra (Outeiro de Rei), mencionada en 757; en Mazoi mencionada en 712 y en 985-998; en Parada (Outeiro de Rei) mencionada en 757 y 897; en Bocamaos mencionada en 995; en Ferreiros (Santa María de Adai) mencionada en 985-998; en Guntin (Santiago de Meilán) mencionada en 757, 760 y 998; en Marcelle (Santiago de Saamasas) mencionada en 757; en Benade mencionada en 747 y 897; en Orbazai mencionada en 985-998; en Acevedo (Santa María de Vilafiz, Friol) mencionada en 841; en Barbaín (Santa María de Bóveda) mencionada en 995; en Lamela (Guntín) mencionada en 747; en Papoi (San Pedro de Calde) mencionada en 995; en Cuiña mencionada también en 995; en Soñar mencionada en 995; en Coeses mencionada en 897; en Argonde (San Juan de Campo) mencionada en 995; en Belesar (San Juan de Campo) en 995; en Recimir mencionada en 745; en Coeo mencionada en 982-999 y 999-1042; en Laxosa (Corgo) mencionada en 900; en Framil (Santa Eulalia de Quinte, Corgo) mencionada en 997; en Quinte (Corgo) mencionada en 747 y 897; en Gomeán (Corgo) mencionada en 982-999; en Reboredo (San Pedro de Bande, Láncara) mencionada en 982-990; en Maceda (Corgo) mencionada en 760.

${ }^{52}$ Como en San Julián de Mos (Castro de Rei) mencionada en 875 y 906; en San Esteban de Benade mencionada en 747 y 897; en Santa Eulalia de Mazoi mencionada en 712; en San Juan de Parada (Outeiro de Rei) mencionada en 747 y 897; en San Julián de Bocamaos mencionada en 760; en Santiago de Meilán mencionada en 712; en Santa Eulalia de Bóveda mencionada en 747; en Santa Eulalia y San Martín de Bolaño (Castroverde) mencionada en 897; en Santa María de Lamela (Guntin) mencionada en 897; en San Pedro de Farnadeiros (Corgo) menciondad en 747; en Santa Eulalia de Quinte (Corgo) mencionada en 897; en Santiago de Laxosa (Corgo) mencionada en 900; en San Miguel de Lapio (Corgo) mencionada en 747.

${ }^{53}$ Como en Santa Eulalia de Bolaño mencionado en 897; en Santiago de Saamasas mencionado en 926; en Santalla (Santa Eulalia de Cuiña) mencionado en 995, 997, 995 999, 995-1017; en Santa María de Ferreira de Pallares (Guntin) mencionado en 898 y 910-924.
}

"CUADERNOS DE ESTUDIOS GALLEGOS", Tomo XLVII, Fascículo 113, Santiago 2000. 

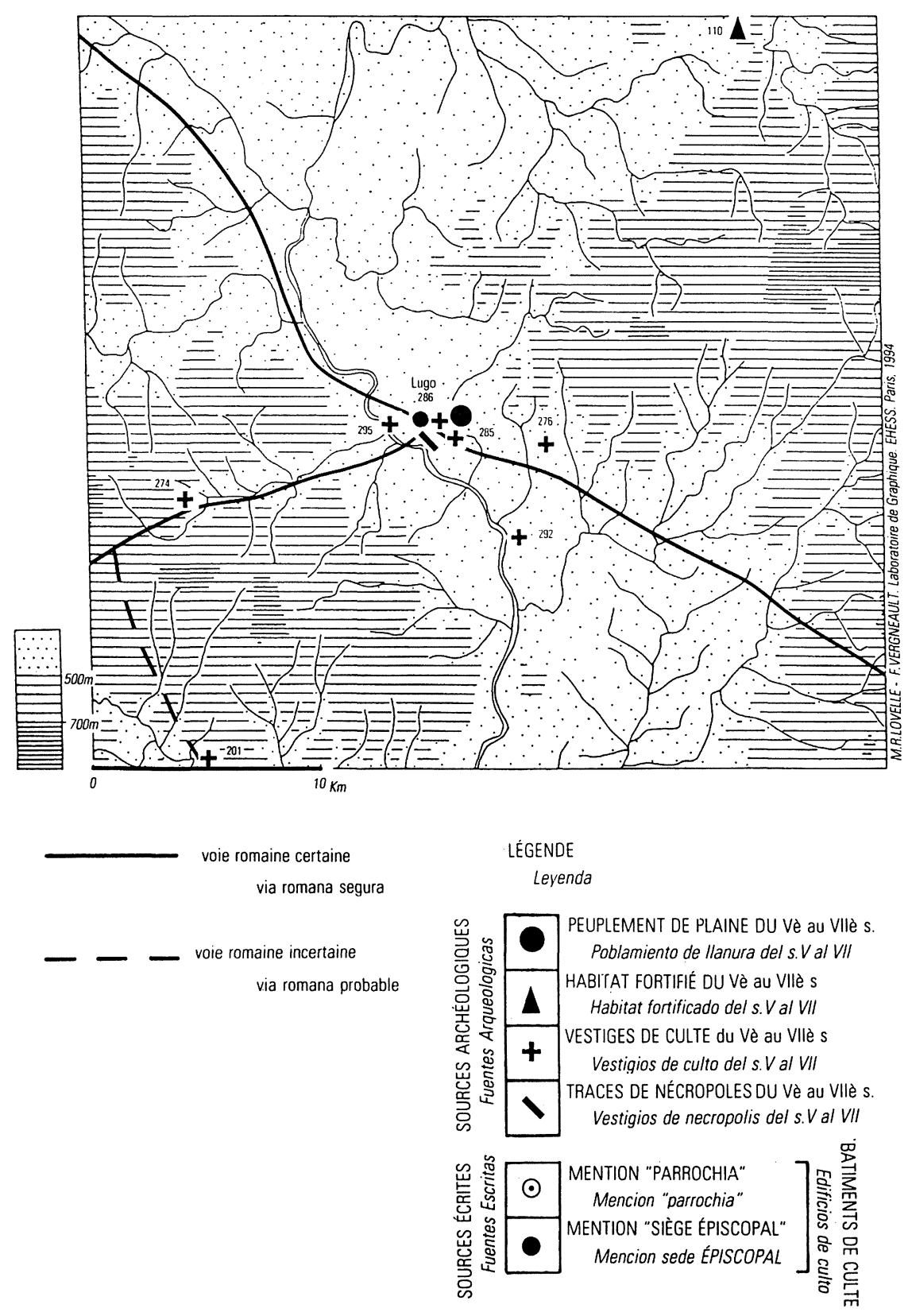

El territorio entorno a Lugo: El poblamiento rural en la época suevo-visigoda (s. V-VII). 


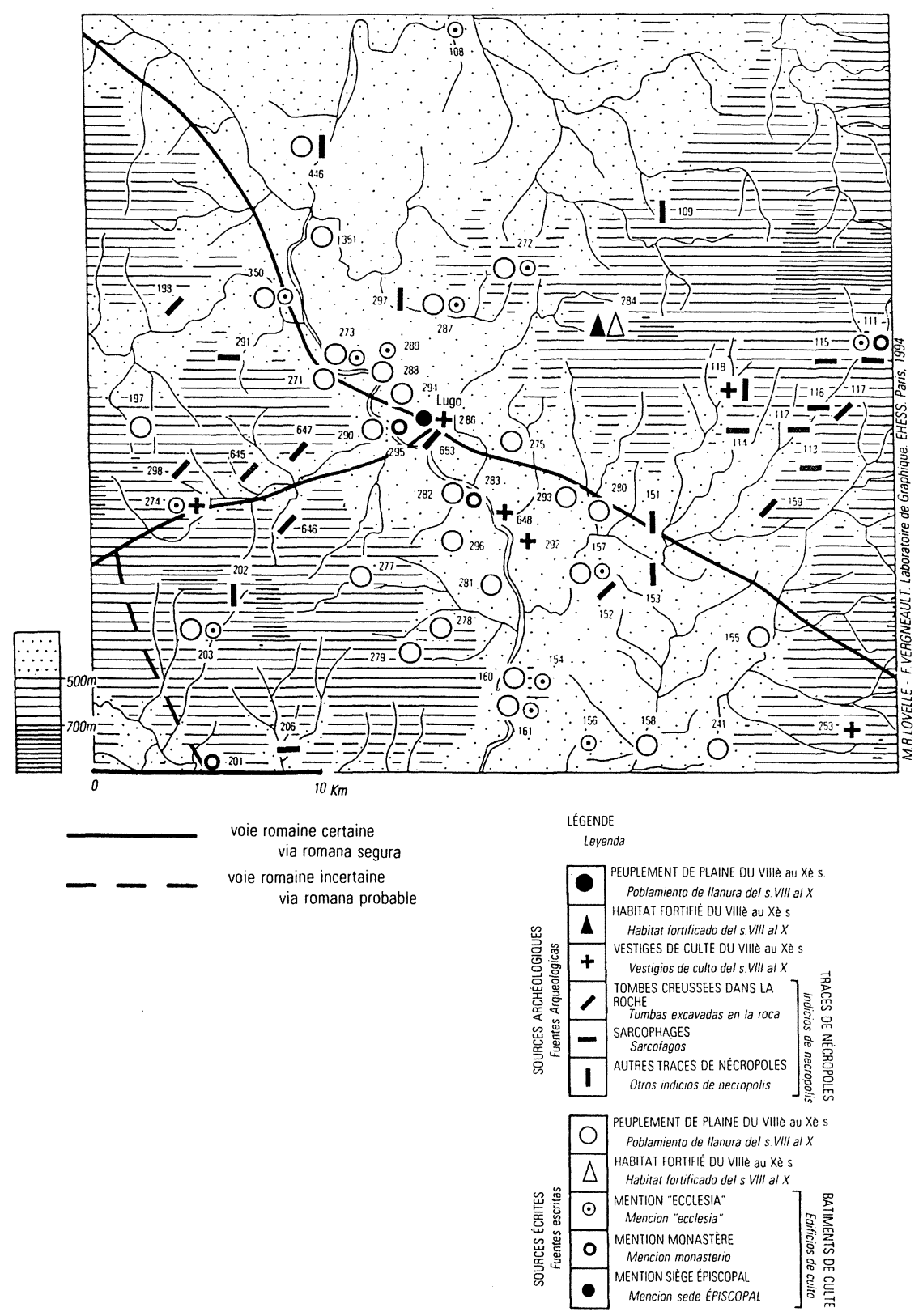

El territorio entorno a Lugo: El poblamiento rural en la época del reino asturiano y de la Reconquista (s. VIII-X) 
cementerios de tumbas antropomorfas excavadas en la roca. La primera observación a efectuar es la de su topografía elevada, generalmente sobre montes o pequeñas elevaciones naturales $\mathrm{y}$, a menudo, muy cerca de castros. Además, estos lugares se sitúan, en general, sobre la curva de nivel de $500 \mathrm{~m}$. Se trata, por lo tanto, de zonas de montaña. Esta ocupación sistemática debe de ponerse en relación con los acontecimientos sociopolíticos del momento: la invasión árabe (y, concretamente, con la llegada de Mousa a Lugo en el 714 y el posible ataque musulmán en el 716$)^{54}$, la probable instalación de guarniciones musulmanas en Lugo, la precipitada salida de los Musulmanes entre el 741 y el 759, y, naturalmente, las campañas militares de Alfonso I hacia estas mismas fechas (741 - 754), siendo Lugo uno de los centros urbanos «arrasados» por este rey ${ }^{55}$. La desorganización del territorio en torno a Lugo (la capital política y religiosa), parece haber tenido un reflejo en la evolución del poblamiento. En este sentido, la crónica mozárabe del 754 nos da informaciones relativamente precisas. Así, después de la invasión del 711, las gentes huyeron hacia las montañas, donde murieron por hambre y por otras causas ${ }^{56}$. El caso preciso de Santa Eulalia de Bóveda podría ayudarnos a esclarecer estos hechos. Ya hemos señalado que Santa Eulalia era un importante lugar de época romana próximo a Lugo, rodeado de castros y en relación con el paso de una importante vía romana. En época suevo-visigoda, el ninfeo romano es reutilizado como edificio de culto paleocristiano con un baptisterio ${ }^{57}$. Posteriormente encontramos una serie de lugares en torno a Santa

${ }^{54}$ C. SÁNCHEZ ALBORNOZ «Itinerario de la Conquista de España por los musulmanes», Cuadernos de Historia de España, VII (1947), p. 21- 57.

${ }^{55}$ J. LÓPEZ QUIROGA - M. RODRÍGUEZ LOVELLE «La invasión árabe y el inicio de la 'Reconquista' en el noroeste de la Península Ibérica (93-251 / 711-865)», Across the Mediterranean Frontiers. Trade, Politics and Religion, 650-1450 (ed. D.A. Agius and I.R. Netton) (International Medieval Research 1, Selected Procedings of the International Medieval Congres, University of Leeds, 10-13 July 1995, 8-11 July 1996), Turnhout, 1997, p. 61- 86.

${ }^{56}$ «...Sicque dum tali terrore cunctos stimulant pacem nonnulle civitates que residue erant iam coacte proclamitant adque suadendo et inridendo astu quoddam nec mora petita condonant. Sed ubi impetrata territi metu recalcitran, ad montana temti iterum effugientes fame et diversa morte periclitant...», J.E. LÓPEZ PEREIRA, Estudio crítico sobre la cónica mozárabe de 754, Zaragoza, 1980, p. 72-73.

${ }^{57}$ A.RODRÍGUEZ COLMENERO - J.M.VÁZQUEZ VARELA, Arte prehistórico $y$ romano ..., op.cit., p. 319-331.

"CUADERNOS DE ESTUDIOS GALLEGOS", Tomo XLVII, Fascículo 113, Santiago 2000. 
Eulalia de Bóveda donde hay pequeños cementerios de tumbas antropomorfas excavadas en la roca situadas a proximidad inmediata de un conjunto de castros. Más concretamente, uno de estos sitios (el más próximo a Santa Eulalia) se localiza sobre la pendiente de un monte llamado «Cubelo». Todo esto, en nuestra opinión, debe de ser explicado en el contexto político de la fuerte oposición de esta zona nororiental de Galicia a la integración política en el reino asturiano ${ }^{58}$. De esta forma, el contacto entre la «desorganizada» sociedad de la parte nororiental de la actual Galicia y la expansión de la monarquía astur, ha dado lugar a confrontaciones y a una fuerte resistencia de las élites y poblaciones locales. En las fuentes cronísticas, como es lógico dado su carácter y procedencia, se habla de una «rebelión de los gallegos» ${ }^{59}$, a continuación se hace referencia a una fuerte oposición por parte de algunos magnates locales tras el asesinato del rey Fruela I, la «rebelión» de época de Aurelio (768-774) ha también podido afectar a nuestro territorio $y$, finalmente, y de especial interés para nosotros, las crónicas nos hablan de la definitiva derrota de los jefes locales «gallegos» por el rey Silo (774-783) ${ }^{60}$. En este último episodio político-militar, es importante subrayar que el pueblo «gallego», al mismo tiempo que mostraba su oposició al rey astur, librará una importante batalla en un monte cerca de Lugo denominado precisamente Cuperio ${ }^{61}$ («... Populos Gallaeciae contre se rebellantes in monte Cuperio bello superauit et suo

${ }^{58}$ Es lo que C.Baiñas denomina la «integración forzada»: C. BALIÑAS, Defensores e traditores: un modelo de relación entre poder monárquico y oligarquia na Galicia altomedieval (718-1037), Santiago de Compostela, 1988; Ibd. Do mito a realidade. A definición social e territorial de Galicia na Alta Idade Media (séculos VIII e IX), Santiago de Compostela, 1992.

${ }^{59}$ En las versiones «Rotense» y «Ovetense» de la Crónica de Alfonso III. Y. BONNAZ, Chroniques Asturiennes. Fin IXe siècle, CNRS, Paris, 1987.

${ }^{60}$ Ibidem

${ }^{61}$ La identificación entre el monte Cuperio y el actual monte Cubelo (cerca de Santa Eulalia de Bóveda) nos parece perfectamente posible. Sin embargo, el monte Cuperio ha sido anteriormente identificado por C. Sánchez Albornoz con el actual monte «Cubeiro» (Castroverde, Lugo) muy cerca de Lugo (también una zona montañosa alrededor de Lugo, no lejos de otros lugares con cementerios de tumbas antropomorfas excavadas en la roca, lo que de todas formas reforzaría igualmente nuestra interpretación).

"CUADERNOS DE ESTUDIOS GALLEGOS", Tomo XLVII, Fascículo 113, Santiago 2000. 
imperio subiugauit...» $)^{62}$. La ocupación de las zonas montañosas en torno a Lugo (como la de Santa Eulalia) por poblaciones locales ya instaladas en esos lugares, parece algo más que probable para este momento.

- un segundo momento, después de la integración de este territorio en la órbita de la monarquía asturiana, en el cual tendrá lugar la restauración y la reorganización del antiguo poblamiento de época romana y tardo-romana. Ciertas reformas son efectuadas en este momento en el edificio de Santa Eulalia de Bóveda: capiteles, modillones, y otros elementos son ahora añadidos ${ }^{63}$. En la documentación de época asturiana, el lugar de Santa Eulalia es mencionado como ecclesia en los ss. VIII y IX ${ }^{64}$. El objetivo sería el de intentar fijar una población alrededor de un centro de culto antiguo (y, en este caso, en torno a una iglesia «restaurada»).

Otro lugar (algo más al sur-oeste de esta zona), merece también una especial atención en el contexto de la restauración y la reorganización del poblamiento efectuadas por la monarquía astur. Se trata de Santa María de Moreda, que es mencionada en la documentación como villa y ecclesia en 747, en 861 y en 897 . Aquí nos encontramos con una iglesia (la de Santa María) que es fundada en una villa (la de Moreda) por gentes foráneas desde mediados del siglo VIII (si tomamos como válida la fecha del documento $)^{65}$. Además de estas referencias documentales, la información

${ }^{62}$ Según la versión «Ovetense» de la crónica de Alfonso III. Según la versión «Rotense»: «...Gallaeciam sibi revellantem, inito certamine in monte Cuperio...» A. UBIETO ARTETA, Crónica de Alfonso III, Valencia, 1971, p. 40-41.

${ }^{63}$ M. NÚÑEZ RODRÍGUEZ, Arquitectura pre-románica..., op. cit., p. 135-138. En nuestra opinión, sería necesario reinterpretar algunas inscripciones y relieves de Santa Eulalia en el contexto de las restauraciones de época asturiana y, quizás, plantearse la pregunta sobre la posibilidad de una conmemoración de la victoria del rey Silo frente al «pueblo gallego» en este lugar (como sería el caso de San Xés de Francelos en el curso medio del Miño).

${ }^{64}$ Concretamente en el controvertido testamento del obispo Odoario en el $747 \mathrm{y}$ en una confirmación de Alfonso III en el 897.

${ }^{65}$ «...ego Toresarius presbiter verum est quod negare non valet quia adnoscens agnosco veritatem eo quod meus abolus Donatus et mater mea Cenosinda propii fuerunt de pleue eclesie et familia bracalese sedis et fecerunt rationem de tempore domini Oduari aepiscopi per inperantes regnantium. Post obitum illius domini Oduari aepiscopi fecerunt rationem domino Aulfo aepiscopo per suos imperantes Tiusarigu et Ermemiro, Stephanu et Malelum. Dederunt tributum et hommes exactiones per ipsos inperantes sicut et alii de ipsa pleue tam de suas personas quam etiam et de ipsa villa quod uogatum

"CUADERNOS DE ESTUDIOS GALLEGOS", Tomo XLVII, Fascículo 113, Santiago 2000. 
arqueológica nos ofrece una información complementaria fundamental para intentar trazar una secuencia lógica de la evolución del poblamiento. En este sentido, la referencia al castro de Moreda (situado a proximidad inmediata de Santa María de Moreda) nos parece capital para comprender la secuencia de ocupación de este lugar antes y después de la «reorganización» territorial efectuada por la monarquía asturiana.Así, es muy significativo el hecho de que dos tumbas antropomorfas hayan sido excavadas sobre los roquedos que están junto al muro del recinto del castro de Moreda $^{66}$. Podemos intuir, por lo tanto, como el proceso de «reorganización» territorial que lleva a cabo la monarquía asturiana tiene por objetivo, desde el punto de vista de la evolución del poblamiento, el de fijar la población en la llanura, en una villa, alrededor de una ecclesia.

En líneas precedentes hemos visto como la ocupación de las zonas de montaña parece haberse generalizado después de la invasión árabe, ya que la mayor parte de los lugares mencionados están situados sobre la línea de $500 \mathrm{~m}$. de altitud. La generalización de este tipo de hábitat en altura ha debido de tener lugar en este momento, incluso si este fenómeno debe de remontarse a época tardo-romana ${ }^{67}$. Sin embargo, es después de la incorporación de este territorio a la monarquía astur, cuando las zonas de llanura (por debajo de la línea de $500 \mathrm{~m}$.) parecen continuar el desarrollo iniciado en época romana. En efecto, la mayor parte de los lugares mencionados en la documentación escrita y los vestigios arqueológicos considerados como típicamente de época asturiana, son localizados hacia la zona del valle del Miño (por debajo de los $500 \mathrm{~m}$.).

En este mismo contexto de la «reorganización» territorial efectuada por la monarquía asturiana debemos de señalar el caso de Santa Comba de Chamoso. Este lugar es mencionado como ecclesia en la documenta-

\footnotetext{
Morera faciebant ex inde suam rationem et ego per me Toresarius fecit hibidem suam rationem. Post obitum uero de ipsos meus abuus et de mater mea Cenusinda subtrascit me de ipsa pleue ut non darem obsequium in ipsa pleuens sicut fecerunt mei abones et in per (si) extraneauit ipsam uillam quod dicitur Moreta et deditad serbis alienis ut pars eclesie non aueret ibidem iure atque manifestum uerum esse fateor...» L. VÁZQUEZ DE PARGA «Los documentos sobre las presuras del Obispo Odoario de Lugo», Hispania, $X$ (1950), p. 670 (doc. IV).

${ }^{66} \mathrm{M}$. VÁZQUEZ SEIJAS «Sartegos», Boletín de la Comisión de Monumentos de Lugo, VII (1960-1961), p. $138-150$.

${ }^{67}$ cfr. supra nota $n^{\circ} 26$.
}

"CUADERNOS DE ESTUdiOS GALLEGOS", Tomo XLVII, Fascículo 113, Santiago 2000. 
ción ${ }^{68} \mathrm{y}$, concretamente, esta iglesia habría sido fundada hacia mediados del s.VIII por Aloitus y su mujer Icka, que eran gentes foráneas, procedentes del Sur de la Península, que acompañaban al obispo Odoario ${ }^{69}$. He aquí, una vez más, una villa y una ecclesia fundadas por foráneos desde mediados del s.VIII ${ }^{70}$. Señalemos, simplemente, la existencia de otro documento de finales del X (concretamente del 993) que hace referencia a una donación a la iglesia de Santa Comba de Chamoso por una pareja llamada también Aloitus e $I c a^{71}$. Incluso, la arqueología podría confirmar la existencia de población en los alrededores de Chamoso antes de la cuestionada «repoblación» de este territorio. En efecto, una inscripción funeraria del 724 ha sido descubierta en la zona de Chamoso ${ }^{72}$, lo que significa, evidentemente, que en torno a este lugar fue enterrado alguién que habitaba allí desde, por lo menos, principios del s. VIII.

${ }^{68}$ El lugar de Santa Comba de Chamoso no ha podido ser localizado con total precisión y, por esta razón, no figura en la documentación gráfica que acompaña este trabajo. Existen, no obstante, en la actualidad tres parroquias con el nombre de «Chanoso»: la de San Cristobal ( donde fue hallada una inscripción pre-románica ), la de San Bartolomé y, finalmente, la de San Andrés.

${ }^{69}$ «... ego supranominatus Aloitus amonitus in somnis multiotes ut in eadem villa domun Dei edifigarem, iusionem et admonicionem supradicto pontifici retullit quod (ille benigne considerans) iussit nobis construit (sic) ecclesiam in honorem Dei et sancte Columbe uirginis tribuitque nobis adiutorium et omines concessit, quos tenebamus de manu illius, qui erant ex familia illius, ut ecclesiam ipsam construerent, ipse presul ponens propria manu in fundamento lapidem ... domun quam illius construxerunt familia et dotem cimiteriumque et terminos ad stipendia clericorum Deo seruientium disponeret... Sunt uero ipsi termini per termino de Castro Recemiri uenitque in termino Uenatori deinc per ribulo que discurrit ad Mineo et inde per Negrellos uaditque ad uillam quos uocitant Cabanas et inde ubi intrat Flamoso in MIneo...» (01-02-745) L. VÁZQUEZ DE PARGA «Los documentos sobre las presuras del Obispo Odoario...» op. cit, p. 666-667.

${ }^{70}$ Siempre teniendo en cuenta que la documentación «odoariana» está sujeta a dudas en cuanto a su autenticidad: C.BALIÑAS, Do mito a realidade..., op . cit., A. ISLA FREZ, La sociedad gallega en la Alta Edad Media, Madrid, 1992.

${ }^{71}$ «...cuius baseli (ca) ex sita est urbis Gallecie valle Clamosum, inter Mineo et Clamosusum, villa uocabulo quod superius resonat Sancte Columbe, subplex seruus uester Aluitum et uxor mea Icam testamus ad ipsum locum sanctum ad ipse ecclesie Va porcione de omnem nostram ereditatem...» (24-04-993) L. VÁZQUEZ DE PARGA «Los documentos sobre las presuras del obispo Odoario...», op. cit. , p. 671- 674.

${ }^{72}$ N. PEINADO «Epigrafía lucense. Cinco interesantes inscripciones», Boletín de la Comisión de Monumentos de Lugo VII (1960-1961), p. 253- 259.

"CUADERNOS DE ESTUDIOS GALLEGOS", Tomo XLVII, Fascículo 113, Santiago 2000. 
Otros documentos del denominado «ciclo de Odoario» podrían ser también reinterpretados en esta dirección. Por ejemplo, el documento de la fundación de la iglesia de Meilán hacia mediados del VIII ${ }^{73}$, lugar en el que Avezano, co-partícipe con el obispo Odoario en la «repoblación» de Lugo y su entorno, declara haber comprado algunas tierras en el momento de su instalación («...Item terris que pro iusto precio emimus...» ${ }^{74}$. Sin embargo, estas tierras no habrían podido ser vendidas si no hubiese una población en el momento de la llegada de los pressores. La existencia de una población local parece desprenderse pues con claridad («...Omnes habitantes in istris dextris et per illorum terminos que in dotem resonat.... $\rangle^{75}$. La pregunta que se plantéa, a partir de la relectura de la documentación, es la siguiente: ¿dónde habitaba esta población? Este mismo documento nos da (como hemos constatado) indicios en este sentido. Así, por ejemplo, en la descripción de lós límites de la iglesia de Meilán, son numerosas las menciones de castros («...de portu Agari per caral antiqua que iacet per mediam villam de Marcelle et perget iusta illo castro usque ferit in via antiqua que discurrit de civitate pro ad illo castro de Bagasios, postea vadit ad illa vereda que venit de Rovera pro ad villam de Castro et feret .... ${ }^{76}$. Otro documento menciona un 4 ...castrum integrum cum edificiis...» entre las posesiones de la iglesia de Santa María de Lugo ${ }^{77}$. Por lo tanto, esta población local preexistente ha debido estar vinculada con toda probabilidad a un tipo de hábitat de altura en castros, que parecen constituir un elemento capital del poblamiento anterior a la «reorganización» astur.

Finalmente, haremos algunas consideraciones sobre el conocido relato de la restauración de Lugo y el «repoblamiento» de su territorio por el Obispo Odoario. Como sabemos por dicho documento ${ }^{78}$, el mencionado obispo establece hacia mediados del s. VIII a siete miembros de su «fami-

\footnotetext{
${ }^{73}$ Concretamente en 757. A. GARCÍA CONDE «Documentos Odoarianos. Documentos de Meilán», Boletín de la Comisión de Monumentos de Lugo, IV (1951), p. 244 245.

${ }^{74}$ L. VÁZQUEZ DE PARGA «Los documentos sobre las presuras...», op. cit., p. 669.

${ }^{75}$ Ibidem.

${ }^{76}$ Ibidem.

${ }^{77}$ Ibidem, p. 679.

${ }^{78}$ Ibidem, p. 663-664.
}

"CUADERNOS DE ESTUdIOS GALLEGOS", Tomo XLVII, Fascículo 113, Santiago 2000. 
lia» sobre siete lugares diferentes, tomando estos lugares el nombre de sus «fundadores», con el objetivo de «repoblar» el territorio entorno a $\operatorname{Lugo}^{79}$. ¿Cuál es el verdadero significado de este relato novelesco y al mismo tiempo simbólico?, ¿qué quiere decir todo esto desde el punto de vista de la evolución y de la organización del poblamiento? Está claro que se trata de un relato figurado que debe de ser reinterpretado en el contexto de la reinstalación de un nuevo poder político sobre este territorio ${ }^{80}$, reorganizando el poblamiento preexistente. El objetivo sería doble: por una parte, intentar fijar la población sobre lo que serán las unidades básicas del poblamiento, las villas, organizadas en función de una iglesia; por otra parte, reorganizar el poblamiento preexistente (mayoritariamente en lugares de altura, sean castros o simples montes) hacia los lugares de llanura. Una progresiva restauración de las antiguas estructuras de poblamiento (las villae de época romaná) y un relanzamiento del proceso de cristianización rural, interrumpido por los acontecimientos de principios y mediados del s. VIII (antiguas iglesias son restauradas de nuevo más que «construidas» $)^{81}$, son dos procesos que parecen haberse producido al mismo tiempo que la creación de nuevas villae y ecclesias. Habría, por lo tanto, una reestructuración del poblamiento a partir del antiguo substrato de época tardo-romana.

\section{CONCLUSIÓN}

Para finalizar, haremos algunas observaciones sobre la evolución del poblamiento en esta microregión. Una zona de gran densidad de castros, sobre la que se crea ex-nuovo una ciudad como Lucus Augusti (capital del conventus Lucense), que sirve de polo central para los castros de la zona. A partir de este núcleo central la vertebración y la organización del territorio en época romana se realiza a partir de la red viaria y la existencia de una serie de establecimientos rurales tipo villae. La romanización de este

\footnotetext{
${ }^{79}$ Ibidem.

${ }^{80}$ J. LÓPEZ QUIROGA - M. RODRÍGUEZ LOVELLE «La invasión árabe y el inicio de la 'Reconquista' en el noroeste de la Península Ibérica...», op. cit. , p. 61- 86.

${ }^{81}$ Como, por ejemplo, Santa Eulalia de Bóveda.
}

"CUADERNOS DE ESTUDIOS GALLEGOS", Tomo XLVII, Fascículo 113, Santiago 2000. 
espacio parece producirse, sin embargo, no en época alto-imperial sino tardo-romana y continúa durante el período que denominamos antigüedad tardía con la cristianización de los núcleos romanos más importantes. Los acontecimientos políticos del comienzos del s. VIII parecen dar un golpe fatal a este tipo de organización territorial y a la estructura del poblamiento típicamente romanas, con una acentuación del hábitat de altura, que pasa a jugar un papel fundamental. Fenómeno que debe de relacionarse con el resurgir del substrato pre-romano hacia finales del s.VII ${ }^{82}$. En todo caso, esta ocupación sistemática de las zonas de montaña (sean montes o antiguos castros) parece generalizarse en el s.VIII, no sólo en relación con la invasión árabe, sino también con las sucesivas campañas militares de los reyes asturianos contra las poblaciones locales preexistentes que, encaramadas en lo alto de los montes, resistirían tenazmente a la integración política y territorial en la monarquía astur ${ }^{83}$. Tras esta integración, la reorganización del poblamiento tiene lugar bajo forma de restauraciones ${ }^{84} \mathrm{y}$, sin duda, nuevas creaciones. La reorganización así efectuada intenta retomar y, en cierta medida, continuar la acción iniciada por Roma, a partir de dos elementos básicos: las villae y las ecclesias.

${ }^{82}$ P.PALOL «Problema Ciudad-Campo en el bajo Imperio...», op. cit, p. 157-173.

${ }^{83}$ Es necesario, en este sentido, poner en relación las campañas de los reyes asturianos (por ejemplo, las de Alfonso I) con las realizadas por Pipino «el breve» en la Galia tanto contra los árabes como contra las poblaciones locales que se oponían a su expansión. G. FOURNIER «Les campagnes de Pépin Le Bref en Auvergne et la question des fortifications rurales au VIIIe siècle», Francia, 2 (1974), p. 123-135; M. ROUCHE, L'Aquitaine des Wisigoths aux Arabes (418-781), Paris, 1977.

${ }^{84}$ De iglesias y de antiguas villae, como lo prueba la expresión «...per suis terminis antiquis...».

"CUADERNOS DE ESTUDIOS GALLEGOS", Tomo XLVII, Fascículo 113, Santiago 2000. 